\title{
Effect of wave exposure dynamics on gut content mass and growth of young-of-the-year fishes in the littoral zone of lakes
}

\author{
S. Stoll ${ }^{*} \dagger$, H. Hofmann* AND P. FISCHER \\ *Limnological Institute, University of Konstanz, 78457 Konstanz, Germany and \\ $\ddagger$ Alfred-Wegener-Institute for Polar and Marine Research, Biologische Anstalt Helgoland, \\ Kurpromenade 201, 27498 Helgoland, Germany
}

(Received 6 May 2009, Accepted 2 February 2010)

\begin{abstract}
Total length, body mass and gut content mass of young-of-the-year (YOY) perch Perca fluviatilis, dace Leuciscus leuciscus and bleak Alburnus alburnus were recorded over the summer of 2006 at three littoral sites at Upper Lake Constance. In P. fluviatilis and L. leuciscus, gut content mass correlated positively with wave-induced energy flux $\left(E_{\mathrm{F}}\right)$ of the respective site and sampling day, while no correlation of gut content mass with $E_{\mathrm{F}}$ was found in A. alburnus. It was assumed that benthivorous $P$. fluviatilis and L. leuciscus profited from suspended or uncovered benthic food items generated by wave action at sites and periods with high $E_{\mathrm{F}}$. Alburnus alburnus, in contrast, feeding mainly on zooplankton in upper parts of the water column, could not profit from increased $E_{\mathrm{F}}$. In $P$. fluviatilis, increased gut content mass during periods of high $E_{\mathrm{F}}$ resulted in higher growth rates. For L. leuciscus, no real growth rates in local fish populations could be determined, as individuals were less sedentary, and when increased growth occurred at sites during the periods of high $E_{\mathrm{F}}$, migration of fish levelled out the resulting size differences within few days. The results of this study show that dynamic habitat variables affect site profitability in the littoral zone of lakes, especially in benthivorous fishes. Therefore, dynamic habitat variables should be considered in addition to fixed habitat properties in analyses of habitat choice of fishes in the littoral zone of lakes.

(C) 2010 The Authors

Journal compilation (C) 2010 The Fisheries Society of the British Isles
\end{abstract}

Key words: Alburnus alburnus; dynamic habitat factor; foraging success; Leuciscus leuciscus; Perca fluviatilis; wave-energy flux.

\section{INTRODUCTION}

One of the key questions in ecology since the emergence of this field of research is how environmental conditions affect the individual organisms and populations that live in a habitat (Chapman, 1931). In lake fish ecology, many studies are available that investigated the effects of fixed physical properties of a habitat such as substratum type, submerged plant coverage, water depth or complexity of habitat structure on diversity and density of fish populations (Tonn \& Magnuson, 1982; Lyons, 1987; Benson \& Magnuson, 1992; Bryan \& Scarnecchia, 1992; Chick \& McIvor, 1994;

$\dagger$ Author to whom correspondence should be addressed. Tel.: +49 7531 883216; fax: +49 7531 883533; email: stefan.stoll@uni-konstanz.de 
Pierce, 1994; Fischer \& Eckmann, 1997; Lewin et al., 2004) as well as on species interactions as competition and predation (Savino \& Stein, 1989a, b; Pierce, 1994; Dietrich et al., 2004).

A typical problem that arises when collecting fish samples for such studies is that the variability between replicate samples is high and large parts of this variability typically remain unexplained by fixed physical habitat properties (Jackson et al., 2001). Some of this remaining variability may be explained by dynamic habitat variables. Dynamic habitat variables may change in an irregular way throughout the sampling period, thereby affecting the profitability of habitats over time. Wildhaber \& Crowder (1990) showed that fishes can respond rapidly to changes in site profitability.

In stream ecology, dynamic habitat variables are well studied. Discharge, and thereby current velocity, is often regarded as the most important dynamic habitat variable affecting costs of activity, food accessibility and predation pressure (Schlosser, 1985). Habitat use varies with discharge for a number of species, including juvenile grayling Thymallus thymallus (L.) (Valentin et al., 1994), brown trout Salmo trutta L. (Heggenes, 1988) and Atlantic salmon Salmo salar L. (Debowski \& Beall, 1995). Growth and survival of young-of-the-year (YOY) fishes may also be affected (Schiemer et al., 2001).

In lake ecosystems, in contrast, the role of dynamic habitat variables is poorly investigated. Studies comparing the energy budget of littoral fishes in different habitats, however, suggest that in littoral habitats, activity costs of fishes may be significant and much more variable than previously assumed (Boisclair \& Leggett, 1989; Boisclair \& Tang, 1993).

Hydrodynamic stress is not restricted to rivers and streams. Fishes living in the littoral zone of lakes are also exposed to significant water movements created by wind-generated waves and, increasingly, to anthropogenic waves generated by ships. The hydrodynamic stress from such waves may impose significant energetic costs on littoral fishes (Stoll et al., 2008), but these may be balanced by gains derived from wave action. Lienesch \& Matthews (2000) showed that daily abundances of some littoral fish species correlate positively with wave variables, possibly because of improved feeding opportunities resulting from suspension of benthic food items (Gabel et al., 2008).

Temperature is another important dynamic habitat variable affecting physiological processes in fishes (Jobling, 1994). Temperature trajectories vary within sites from day to day and also between sites due to the degree of shading by shoreline vegetation and local water currents. Thus the profitability of different sites is influenced by temperature in potentially irregular and unpredictable ways.

This study examines the effect of dynamic habitat variables, wave energy flux $\left(E_{\mathrm{F}}\right)$ and temperature on the juvenile fish populations at three different sites in Lake Constance over a three-month period in summer 2006. Three focal species, perch Perca fluviatilis L., dace Leuciscus leuciscus (L.) and bleak Alburnus alburnus (L.), were sampled at three different sites at intervals of 7-14 days. In the first step, a test was made of whether gut content mass, and thus feeding success, depends on ambient wave energy flux and temperature. The three focal species were chosen because they differ in feeding strategy. During the summer months, the diet of $P$. fluviatilis $<95 \mathrm{~mm}$ total length $\left(L_{\mathrm{T}}\right)$ comprises mostly benthic invertebrates in the littoral zone (Schleuter \& Eckmann, 2008). Juvenile L. leuciscus also feed on benthic invertebrates. In addition, L. leuciscus consume epilithon (Weatherley, 1987), 
which they scrape from hard substrata with their horny lower lip. Gut content mass of these species should correlate with $E_{\mathrm{F}}$, as they can profit from resuspension of benthic food items. Alburnus alburnus, in contrast, typically swim further up in the water column feeding on planktonic prey and wind-borne items from the water surface (Białokoz, 1990; Vašek \& Kubečka, 2004). The availability of these prey types is not influenced by resuspension and thus should not be correlated with $E_{\mathrm{F}}$. A second step tested whether differences in feeding success related to $E_{\mathrm{F}}$ resulted in growth differences in the local fish populations. It was assumed that the effect of $E_{\mathrm{F}}$ on local fish growth rates could be found in P. fluviatilis and L. leuciscus, but not in A. alburnus.

\section{MATERIALS AND METHODS}

\section{STUDY AREA}

Lake Constance is a large, warm-monomictic pre-alpine lake situated at the boundary of Germany, Switzerland and Austria $\left(47^{\circ} \mathrm{N} ; 09^{\circ} \mathrm{E}\right)$ at an altitude of $395 \mathrm{~m}$ a.s.l. The lake comprises two basins, the deep oligotrophic Upper Lake Constance and the relatively shallow, mesotrophic Lower Lake Constance [Fig. 1(a)]. The wave field of Lake Constance is characterized by wind waves and periodically occurring ship waves (Hofmann et al., 2008). With the exception of private boating, most ship traffic is scheduled and hence more or less consistent between days throughout the whole summer. The contribution of wind waves varies with wind intensity and direction. Over the period of a year, the prevailing winds over Lake Constance are westerlies, with the second most frequent winds coming from the south-east during summer and north-east during winter.

The three sampling sites used in this study were littoral areas located in the north-western area of Upper Lake Constance. They were selected with respect to maximal uniformity on the basis of abiotic and biotic habitat variables such as substratum quality, angle of inclination

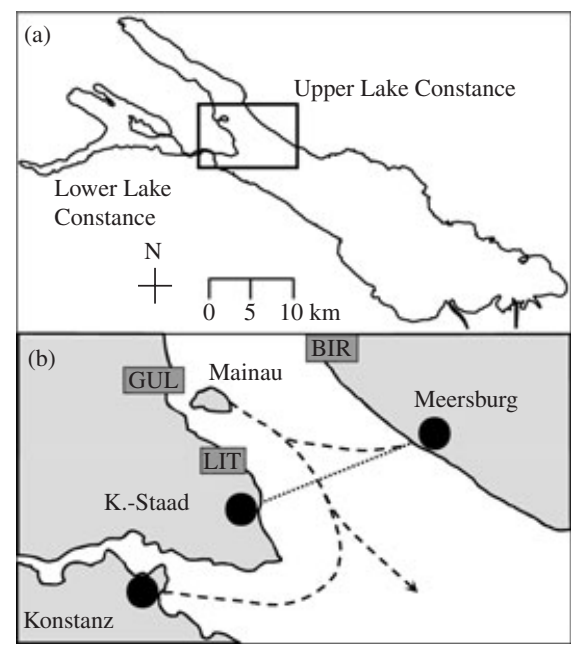

FIG. 1. (a) Map of Lake Constance, situated at the border between Germany, Switzerland and Austria. (b) Magnification of ( $\square$ ) in (a). Three sampling sites: Birnau (BIR), Lower Güll (GUL) and Littoral Garden (LIT). ....., the ferry line between Konstanz-Staad and Meersburg. . . ., the passenger ship lines to the Island of Mainau. 
and plant coverage, while exposure to surface waves at each site was different [Fig. 1(b)]. At the seaward edge, they all reach a water depth of 4-5 $\mathrm{m}$. There the bottom drops to water depths $>50 \mathrm{~m}$ with an angle of $c .45^{\circ}$.

Site Birnau (BIR) is located on the northern shoreline. At BIR, the littoral shelf extends c. $150 \mathrm{~m}$ into the lake. BIR is exposed to winds from the south-west, but few ship waves occur at this site. The substratum is characterized by gravel and pebbles, infilled with sandy sediments. Soft sediments predominate in deeper areas ( $>3 \mathrm{~m}$ water depth) with a sparse coverage of submerged macrophytes, mainly Potamogeton pectinatus. A small quantity of Chara spp. is present in all water depths.

Site Lower Güll (GUL) is situated on the south-western shoreline. The littoral width is $c$. $300 \mathrm{~m}$. GUL lies to the northern side of the bay behind the Island of Mainau and is sheltered from both ship and wind waves, with the exception of those driven by a rare straight easterly wind. The substratum is dominated by pebbles in the shallow $(<0.5 \mathrm{~m})$, and at greater depth by sandy or soft sediments, the latter covered with Chara spp.

The site Littoral Garden (LIT) is also situated on the south-western shoreline, c. $3 \mathrm{~km}$ south-east of GUL. The littoral width is $c .80 \mathrm{~m}$. LIT is fully exposed to frequent ship waves generated by the car ferries shuttling between the cities of Konstanz-Staad and Meersburg, and by passenger ships heading to and from the Island of Mainau. On average, ship waves contribute $40-50 \%$ of the total $E_{\mathrm{F}}$ to this part of the shoreline during the main navigation period in summer and $41 \%$ over the whole year (Hofmann et al., 2008). The substratum at LIT is dominated by sand and pebbles, interspersed with few stones. Submerged macrophyte coverage is sparse during summer, comprising mainly Chara spp. and some P. pectinatus and Potamogeton perfoliatus L., the last two only present at water depths between 3 and $5 \mathrm{~m}$.

\section{FISH SAMPLING}

Sampling was conducted at the three sampling sites on a weekly to bi-weekly basis between July and October 2006 (Table I). Fishes were caught in a beach seine $16 \mathrm{~m}$ long and $1.5 \mathrm{~m}$ high with a $4 \mathrm{~mm}$ bar mesh, hauled in to the shore from 1.2 to $1.3 \mathrm{~m}$ water depth (the maximum depth that could be reached with waders). On each sampling day, the three sites were sampled in a random order between 1000 and 1600 hours. YOY P. fluviatilis, L. leuciscus and A. alburnus were chosen as focal species, as they represent different feeding behaviour (P. fluviatilis: benthos; L. leuciscus: benthos and epilithon; A. alburnus: plankton) and were most abundant in the seine catches at all three sites, comprising $>95 \%$ of the YOY fishes caught. On each occasion, fishing was continued until 20 individuals of each focal species were caught, or for a maximum of four hauls per site to limit the impact on the site and its fish community. Fishes for analysis were killed immediately with 2-phenoxyethanol solution and stored on ice until they reached the laboratory (maximum $4 \mathrm{~h}$ ) where they were immediately frozen until further processing. Surplus catch not required for the analysis was immediately released.

In the laboratory, fishes were thawed carefully in ice water. $L_{\mathrm{T}}$ was measured to the nearest $0.5 \mathrm{~mm}$ and wet mass $\left(M_{\mathrm{W}}\right)$ was taken $( \pm 0.01 \mathrm{~g})$. Then guts were dissected out, from the oesophagus to the anus. Reliable identification of gut contents was impossible due to the degree of crushing and digestion; thus, only wet mass of the gut contents $\left(M_{\mathrm{GC}}\right)$ was recorded $( \pm 0 \cdot 001 \mathrm{~g})$.

\section{ABIOTIC HABITAT VARIABLES}

Water temperatures were recorded continuously with a sampling resolution of $12 \mathrm{~h}^{-1}$ throughout the whole summer season. A temperature logger (Onset Computer Corp.; www. onsetcomp.com) was moored at $c .1 .25 \mathrm{~m}$ (range $\pm 0.10 \mathrm{~m}$ ) water depth at each of the three sites, and the position of the loggers was adjusted twice according to the water level. Because temperature data were distributed normally, daily means were calculated for each sampling site for analysis in relation to $M_{\mathrm{GC}}$ and sampling period means for the analysis of population structure development. 
TABLE I. Data coverage during the total sampling period (11 July to 4 October 2006) for abiotic habitat factors temperature and energy flux $\left(E_{\mathrm{F}}\right)$ at the sampling sites Birnau (BIR), Lower Güll (GUL) and Littoral Garden (LIT) (see Fig. 1). Data gaps resulted from battery replacement and theft of one sensor. If data coverage of a sampling period was $<50 \%$, data were not included in the analyses and values in this table are shown in parentheses

\begin{tabular}{|c|c|c|c|c|c|c|}
\hline \multirow[b]{3}{*}{ Sampling periods } & \multirow{3}{*}{$\begin{array}{l}\text { Period } \\
\text { number }\end{array}$} & \multirow{3}{*}{$\begin{array}{l}\text { Days between } \\
\text { samplings }(n)\end{array}$} & \multicolumn{4}{|c|}{ Data coverage $(\%)$} \\
\hline & & & \multirow{2}{*}{$\begin{array}{c}\text { Temperature, } \\
\text { all sites }\end{array}$} & \multicolumn{3}{|c|}{$E_{\mathrm{F}}$} \\
\hline & & & & BIR & GUL & LIT \\
\hline 11 to 18 July & 1 & 7 & 100 & 85 & 100 & $(0)$ \\
\hline 18 to 31 July & 2 & 13 & 100 & 50 & 100 & $(45)$ \\
\hline 31 July to 9 August & 3 & 9 & 100 & $(0)$ & 100 & 80 \\
\hline 9 to 18 August & 4 & 9 & 100 & (20) & 85 & 100 \\
\hline 18 to 31 August & 5 & 13 & 100 & 100 & 100 & 100 \\
\hline 31 August to 12 September & 6 & 12 & 100 & 100 & 100 & 90 \\
\hline 12 to 19 September & 7 & 7 & 100 & 85 & 83 & 100 \\
\hline 19 September to 4 October & 8 & 15 & 100 & 100 & 100 & 100 \\
\hline
\end{tabular}

Surface wave fields at each of the three sites were monitored using custom-made pressure sensors (PS; based on sensor PDCR 1730, GE Druck; www.gesensing.com; refitted for longterm energy supply and data storage at the Technical workshop of the University of Konstanz), deployed at a water depth of $2 \mathrm{~m}$. The stands of the PSs were $1 \mathrm{~m}$ high, and thus measurements were recorded in the middle of the water column. Each PS had a full-scale range of $7 \mathrm{~m}$, an accuracy of $0 \cdot 1$ mbar and a maximum stand-alone deployment time of 45 days. Pressure measurements were made at a sampling frequency of $16 \mathrm{~Hz}$ during the entire deployment period. Data gaps resulted from battery replacement, which had to be done in the workshop, and the theft of one sensor. The subsurface pressure measurements were converted to a time series of surface elevation following the procedure described by Hofmann et al. (2008). Wave variables (i.e. wave height and period) were estimated for sets of 1024 (64 s) samples using the zero-upcrossing method (IAHR, 1989; Hofmann et al., 2008). Wave energy flux $\left(E_{\mathrm{F}}\right)$ is an ecologically relevant property of wave action (Hofmann et al., 2008). $E_{\mathrm{F}}$ associated with motion per unit length of wave crest $\left(\mathrm{W} \mathrm{m}^{-1}\right)$ can be estimated as the product of group velocity and wave energy using the formulas given in Hofmann et al. (2008). $E_{\mathrm{F}}$ data were skewed, especially at the site LIT, where low background values throughout most of the day were punctuated by short periods of high $E_{\mathrm{F}}$ values, when a ship was passing the site. Therefore, for $E_{\mathrm{F}}$, daily medians and sampling interval medians were used for the analyses.

\section{DATA PROCESSING AND STATISTICS}

For each of the focal species, $M_{\mathrm{GC}}$ of individual fishes were analysed with respect to site, $M_{\mathrm{W}}$ without stomach content $\left(M_{\mathrm{W}}-M_{\mathrm{GC}}\right)$, median $E_{\mathrm{F}}$ of the sampling date and mean temperature of the sampling date using general linear models (GLM). For continuously scaled variables $\left(M_{\mathrm{W}}, E_{\mathrm{F}}\right.$ and temperature), slope estimates are given to indicate the direction of the correlation. $t$ post hoc tests were applied when effects of the nominally scaled variable site were found.

The mean absolute growth rate $G$ of the local fish populations at the three sampling sites was calculated for each species: $G=\left(M_{i}-M_{i-1}\right) \Delta t^{-1}$, where $M_{i}$ is the average body mass in a fish population at sampling $i$, and $\Delta t$ is the number of days between the samplings $i$ and $i$-1. Since open YOY fish populations were sampled in this study, the composition of the fish populations sampled at any one site may have varied throughout the sampling season. Therefore, the calculated growth rates may reflect not only growth, but also emigration from or immigration into a local fish population. 
The growth rates were based on $M_{\mathrm{W}}$, so no systematic change in magnitude occurred during the summer season (ANOVA testing the effect of week of year on growth rate: $F_{1,52}=0.34$, $P>0.05$ ). Development of $L_{\mathrm{T}}$, in contrast, followed a logarithmic function, and thus growth rates based on $L_{\mathrm{T}}$ were highest during early summer and declined towards the end of the summer. Where a sampling session at a site yielded fewer than four individuals of a focal species, data were not included in the analysis.

To elucidate whether local fish growth rates were dependent on dynamic abiotic habitat variables, the growth rates of each of the three focal species were related to site, $E_{\mathrm{F}}$ and temperature of the respective periods using general linear models (GLM). $t$ post hoc tests were applied when effects of the nominally scaled variable site were found.

All tests were performed with a significance level of $P=0 \cdot 05$. Only periods with $E_{\mathrm{F}}$ data coverage $>50 \%$ were included in the analysis (Table I). Before each test, normal distribution and homogeneity of variances were tested using Shapiro-Wilk's and Bartlett tests and appropriate tests for further data analysis were chosen accordingly (Lozàn \& Kausch, 1998).

\section{RESULTS}

Fish were sampled nine times in the summer of 2006 at each of the three sampling sites BIR, GUL and LIT. A total of 1213 YOY fishes were caught for analysis, among them were 330 P. fluviatilis, 430 L. leuciscus and 453 A. alburnus (Table II). Perca fluviatilis were present throughout the whole summer season at GUL and from 31 July at the site LIT. At BIR, P. fluviatilis occurred only incidentally. Leuciscus leuciscus were present at all three sampling sites from the beginning of the sampling. The sampling at 31 July and 9 August at GUL yielded insufficient numbers of L. leuciscus for analysis. Alburnus alburnus were present at BIR from the beginning of the study and appeared at GUL on 17 July and at LIT on 31 July and remained present at all sites throughout the rest of the summer (Table II).

The $L_{\mathrm{T}}$ and $M_{\mathrm{W}}$ of $P$. fluviatilis, L. leuciscus and A. alburnus generally increased throughout the summer, though there were some periods, over which mean $L_{\mathrm{T}}$ and $M_{\mathrm{W}}$ of local fish populations decreased between consecutive sampling dates (Fig. 2). In $P$. fluviatilis, in particular, mean $L_{\mathrm{T}}$ and $M_{\mathrm{W}}$ did not increase synchronously at the sites GUL and LIT, and after 12 September 2006 (end of sampling period six), $L_{\mathrm{T}}$ and $M_{\mathrm{W}}$ of $P$. fluviatilis at LIT were significantly higher than at GUL ( $t$-test, 12 September 2006: d.f. $=32, t=5.01, P<0.001 ; 19$ September 2006: d.f. $=38$, $t=7.93, P<0.001$; 04 October 2006: d.f. $=36, t=7.13, P<0.001)$.

Daily median $E_{\mathrm{F}}$ in the range between 0.02 and $18.5 \mathrm{~W} \mathrm{~m}^{-1}$ was measured at the three sampling sites [Fig. 3(a)]. Daily median $E_{\mathrm{F}}$ intensities differed significantly between the three sampling sites (median test: $\chi^{2}=140$, d.f. $=2, P<0 \cdot 001$ ). The lowest $E_{\mathrm{F}}$ values were recorded at the most protected site GUL, with an exception on 17 July [Fig. 3(a)]. Intermediate wave energy fluxes were recorded at BIR, and highest values were measured at LIT. A strong wave event occurred at BIR on 29 August, and at LIT on 8 September, resulting in peak median $E_{\mathrm{F}}$ in sampling period five in BIR and six in LIT [Fig. 3(a)-(c)].

Daily mean water temperatures recorded during the entire sampling period ranged between 14.5 and $27.2^{\circ} \mathrm{C}$ [Fig. 3(d)]. Daily mean water temperatures did not differ significantly between sampling sites (ANOVA for paired data: $F_{2,257}=1.99$, $P>0 \cdot 05)$; however, using sampling period means, significant differences could be found (Friedman test: $X r^{2}=12 \cdot 3, P<0 \cdot 05$ ), as during all sampling periods, the average temperature was $0 \cdot 5-1 \cdot 5^{\circ} \mathrm{C}$ higher at site GUL than at sites BIR and LIT 


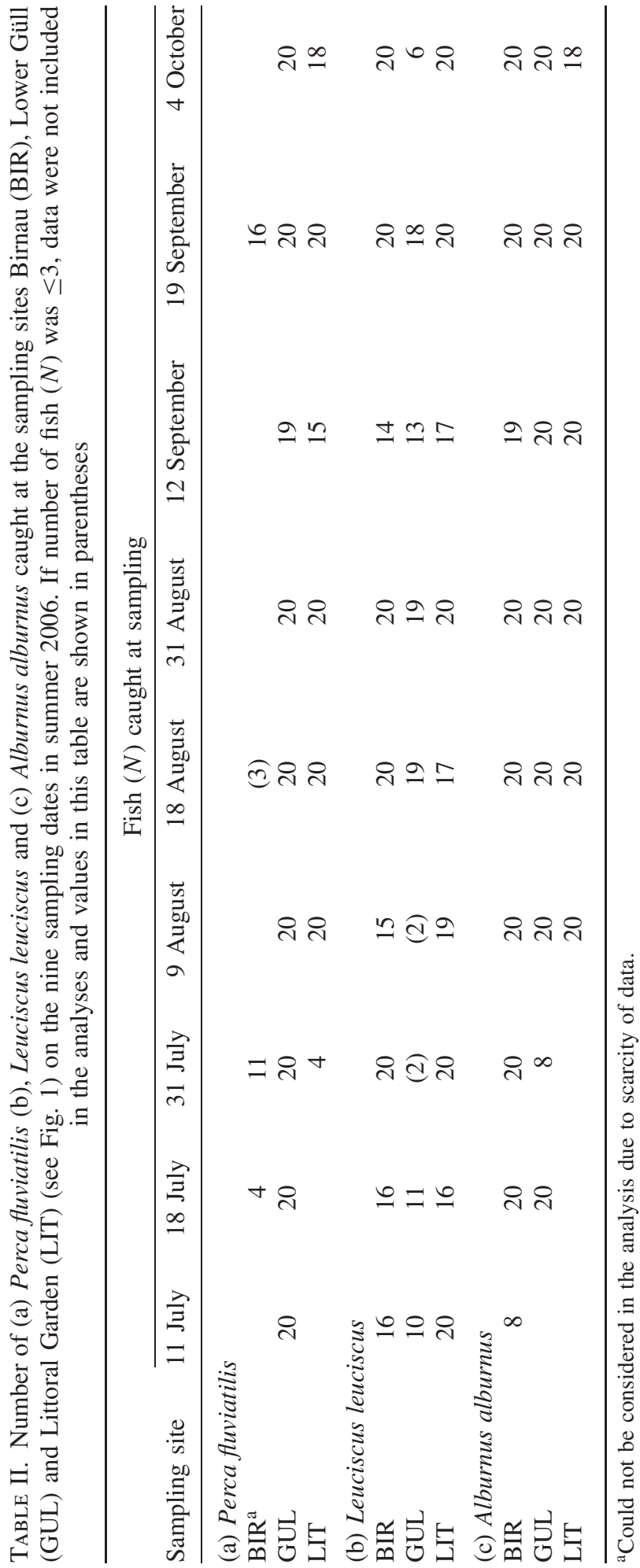



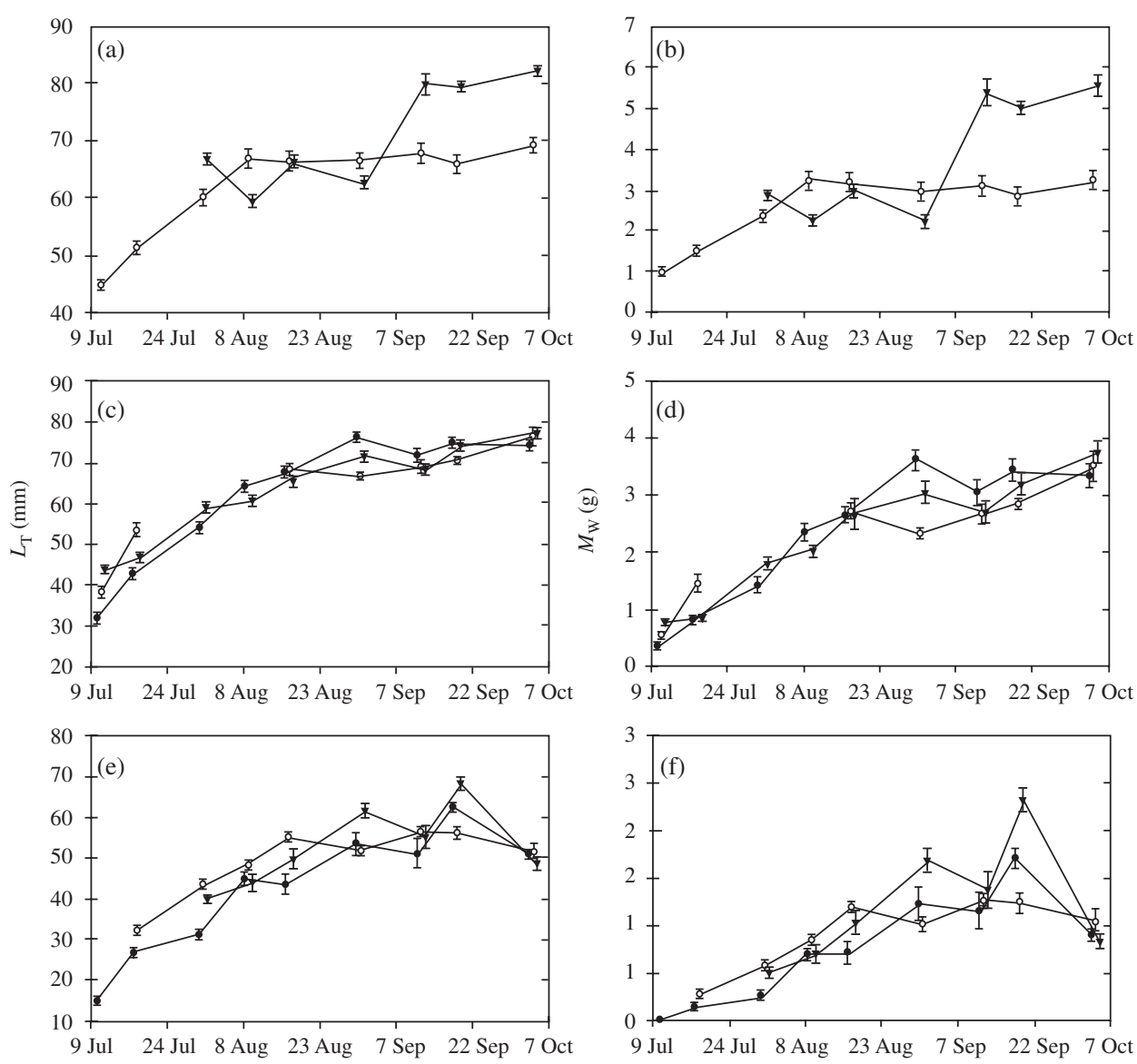

Date

FIG. 2. Mean \pm S.E. (a), (c), (e) total length $\left(L_{\mathrm{T}}\right)$ and (b), (d), (f) wet body mass $\left(M_{\mathrm{W}}\right)$ of the three fish species (a), (b) Perca fluviatilis (c), (d), Leuciscus leuciscus and (e), (f) Alburnus alburnus throughout the sampling season in summer 2006 at the three sampling sites Birnau (@), Lower Güll (O) and Littoral Garden ( $)$ (see Fig. 1).

[Fig. 3(e), (f)]. A drop in water temperature occurred during the first days of August, when strong winds caused upwelling of colder water at all three sites.

No completely empty guts were found. In all three fish species, $M_{\mathrm{GC}}$ was highly correlated with $M_{\mathrm{W}}$ (Table III). The $M_{\mathrm{GC}}$ differed significantly between sites in all species. Post hoc tests revealed that P. fluviatilis and L. leuciscus consumed significantly more food at LIT than at the other sites, and A. alburnus consumed more food at GUL than at BIR, with intermediate consumption at LIT. In P. fluviatilis and L. leuciscus, $M_{\mathrm{GC}}$ correlated positively with $E_{\mathrm{F}}$ and with temperature, but not in A. alburnus (Fig. 4).

In $P$. fluviatilis, growth rates differed significantly between sites, with lower values at GUL than at LIT (Table IV). Furthermore, increase in $M_{\mathrm{W}}$ was positively correlated with $E_{\mathrm{F}}$ but not with temperature. In L. leuciscus and A. alburnus, no 

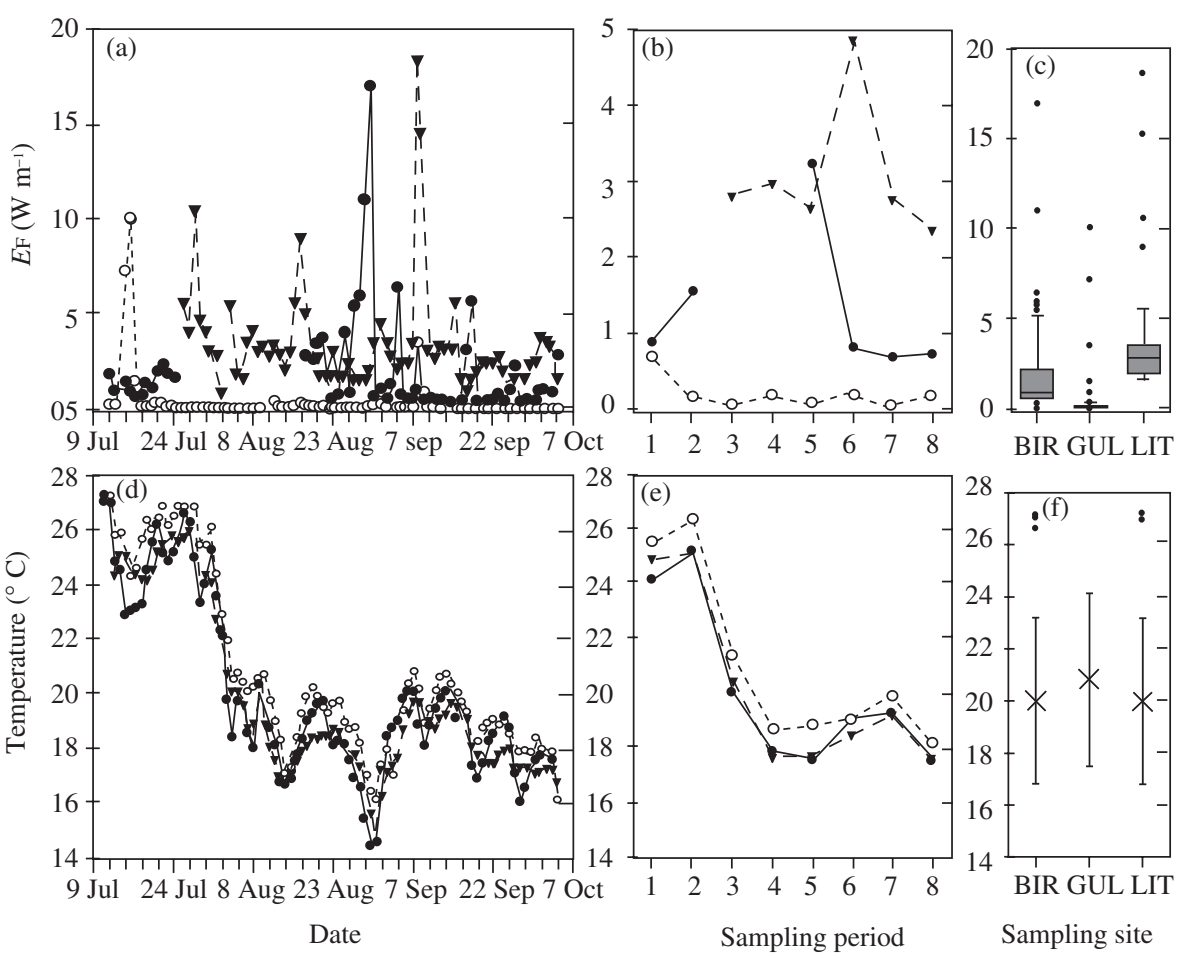

Fig. 3. (a), (b), (c) Wave energy flux $\left(E_{\mathrm{F}}\right)$ at $1.25 \mathrm{~m}$ water depth and (d), (e), (f) water temperature at the sampling sites Birnau (BIR, ○), Lower Güll (GUL, O) and Littoral Garden (LIT, $\mathbf{\nabla})$ (see Fig. 1). Daily (a), (d) (b), (e), sampling period and (c), (f) whole summer medians of $E_{\mathrm{F}}$ and means of water temperature are given, respectively. For whole summer medians of $E_{\mathrm{F}}, 10 \mathrm{th}, 25 \mathrm{th}, 75$ th and 90 th percentiles and outliers are plotted, while S.D. and outliers of double S.D. are given for whole summer means of temperature. Significant differences in $E_{\mathrm{F}}$ (Nemenyi post hoc test) and water temperature (Wilcoxon-Wilcox post hoc test) between sites are indicated with different uppercase letters.

significant correlations between increase in $M_{\mathrm{W}}$ and site, $E_{\mathrm{F}}$ and temperature could be found (L. leuciscus: total $R^{2}=0.05$, all $P>0.05 ;$ A. alburnus: total $R^{2}=0.03$, all $P>0.05)$.

\section{DISCUSSION}

This study shows that local YOY fish populations in littoral habitats of a lake respond to dynamic changes in abiotic environmental variables. According to the predictions, $M_{\mathrm{GC}}$ mass of benthivorous $P$. fluviatilis and L. leuciscus correlated positively with $E_{\mathrm{F}}$. It is assumed that in periods when wave action and thus $E_{\mathrm{F}}$ were high, benthic food items were suspended, or at least uncovered at the substratum surface, and that $P$. fluviatilis and L. leuciscus profited from the resultant increase in food accessibility (Lienesch \& Matthews, 2000). This mechanism was previously demonstrated by Gabel et al. (2008) in laboratory studies, showing that benthic invertebrates may be lifted into suspension in the water column by waves, especially where 
TABLE III. General linear model (GLM) results analysing the gut content mass $\left(M_{\mathrm{GC}}\right)$ of (a) Perca fluviatilis, (b) Leuciscus leuciscus and (c) Alburnus alburnus. In order to give the direction of the correlation, slope estimates (mean \pm s.E.) are given if the variable is scaled continuously. The results of $t$ post hoc tests are given for the nominally scaled variable site. Different uppercase letters indicate significant differences, the highest value is assigned to the letter A, the order of the three sites is alphabetical, Birnau (BIR), Lower Güll and Littoral Garden

\begin{tabular}{|c|c|c|c|c|c|}
\hline Variable & d.f. & $S S$ & $F$ & $P$ & $\begin{array}{c}\text { Slope estimate } \\
\text { post hoc test results }\end{array}$ \\
\hline \multicolumn{6}{|c|}{ (a) Perca fluviatilis, $R^{2}=0.65$} \\
\hline$M_{\mathrm{W}}$ & 1 & 307034 & 342 & $<0.001$ & $33.79 \pm 1.83$ \\
\hline Site $^{\mathrm{a}}$ & 1 & 4125 & $4 \cdot 60$ & $<0 \cdot 05$ & (a) B, A \\
\hline$E_{\mathrm{F}}$ & 1 & 8410 & $9 \cdot 37$ & $<0 \cdot 01$ & $7 \cdot 38 \pm 2 \cdot 41$ \\
\hline Temperature & 1 & 27378 & $30 \cdot 50$ & $<0 \cdot 001$ & $3.94 \pm 0.71$ \\
\hline Error & 192 & 203788 & & & \\
\hline \multicolumn{6}{|c|}{ (b) Leuciscus leuciscus, $R^{2}=0.62$} \\
\hline$M_{\mathrm{W}}$ & 1 & 419666 & 294 & $<0 \cdot 001$ & $42 \cdot 35 \pm 2 \cdot 47$ \\
\hline Site & 2 & 19706 & 6.91 & $<0 \cdot 01$ & B, B, A \\
\hline$E_{\mathrm{F}}$ & 1 & 55943 & $39 \cdot 23$ & $<0 \cdot 001$ & $10 \cdot 43 \pm 1.67$ \\
\hline Temperature & 1 & 20684 & $14 \cdot 50$ & $<0 \cdot 001$ & $2 \cdot 86 \pm 0.75$ \\
\hline Error & 425 & 540520 & & & \\
\hline \multicolumn{6}{|c|}{ (c) Alburnus alburnus, $R^{2}=0.61$} \\
\hline$M_{\mathrm{W}}$ & 1 & 107418 & 413 & $<0 \cdot 001$ & $28.48 \pm 1.40$ \\
\hline Site & 2 & 1752 & $3 \cdot 37$ & $<0.05$ & $\mathrm{~B}, \mathrm{~A}, \mathrm{AB}$ \\
\hline$E_{\mathrm{F}}$ & 1 & 100 & $0 \cdot 39$ & $>0.05$ & $-0.57 \pm 0.91$ \\
\hline Temperature & 1 & 170 & $0 \cdot 65$ & $>0.05$ & $-0.23 \pm 0.29$ \\
\hline Error & 448 & 103802 & & & \\
\hline
\end{tabular}

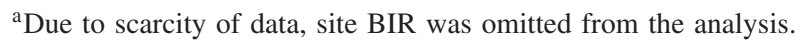

$M_{\mathrm{W}}$, wet body mass; $E_{\mathrm{F}}$, wave energy flux.

TABLE IV. General linear model (GLM) results analysing the effect of sampling site (Birnau, BIR; Lower Güll, GUL; Littoral Garden, LIT), wave energy flux $\left(E_{\mathrm{F}}\right)$ and temperature on the growth of Perca fluviatilis. In order to give the direction of the correlation, slope estimates (mean \pm S.E.) are given in case the variable is scaled continuously. The results of LSM $t$ post hoc tests are given for the nominally scaled variable site

\begin{tabular}{lrrrcc}
\hline Variable & d.f. & $S S$ & $F$ & $P$ & Post hoc test result/slope estimate \\
\hline Perca fluviatilis, & $R^{2}=0.64$ & & & \\
Site $^{\text {a }}$ & 1 & 0.05 & 12.50 & $<0.01$ & LIT $>$ GUL \\
$E_{\mathrm{F}}$ & 1 & 0.07 & 17.28 & $<0.01$ & $0.13 \pm 0.03$ \\
Temperature & 1 & $<0.01$ & 0.03 & $>0.05$ & $0.001 \pm 0.007$ \\
Error & 10 & 0.04 & & & \\
\hline
\end{tabular}

${ }^{\mathrm{a} D u e}$ to scarcity of data, site BIR was omitted from the analysis. 

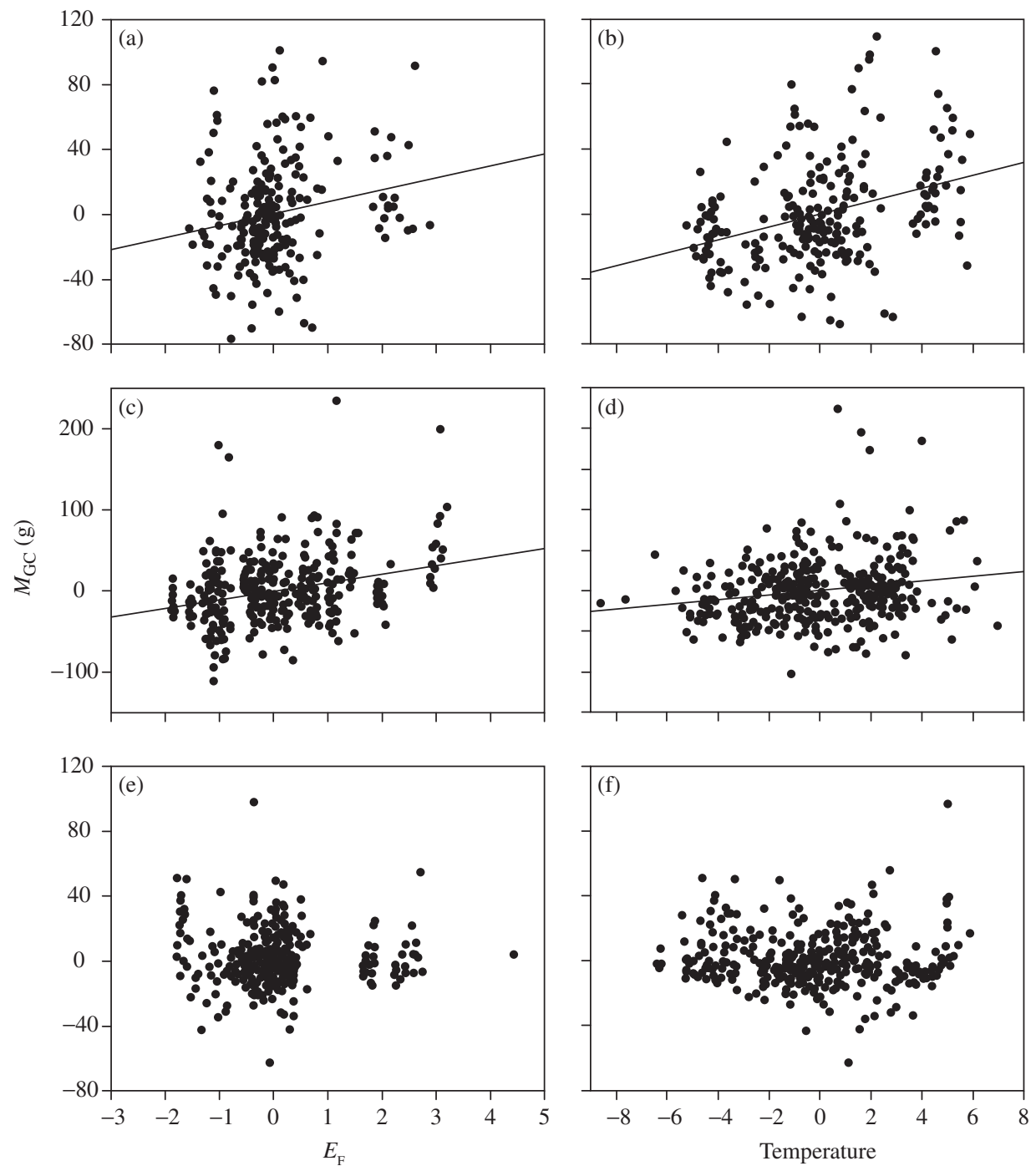

FIG. 4. Partial regression plots showing the relation of gut content mass $\left(M_{\mathrm{GC}}\right)$ of (a), (b) Perca fluviatilis (c), (d) Leuciscus leuciscus and (e), (f) Alburnus alburnus to (a), (c), (e) wave energy flux ( $\left.E_{\mathrm{F}}\right)$ and (b), (d), (f) temperature when all other variables in the model are held constant. On both axes, residuals of the indicated variables are plotted. (a) $P<0.01$; (b) $P<0.001$; (c) $P<0.001$; (d) $P<0.001$; (e) $P>0.05$; (f) $P>0.05$.

the structural complexity of the substratum is low. Also in streams, resuspension of invertebrates resulted in an increased foraging success in some benthivorous fishes (Blanchet et al., 2008).

In planktivorous $A$. alburnus, $M_{\mathrm{GC}}$ did not correlate with $E_{\mathrm{F}}$. Other authors found that planktivores may profit from limited turbulence, but this effect has only been demonstrated for small fish larvae with a restricted mobility, but not for larger fishes 
(MacKenzie et al., 1994; Utne-Palm \& Stiansen, 2002; Utne-Palm, 2004). Furthermore, the levels of turbulence these authors used were much lower than the level of turbulence recorded here.

Rising temperature increased the $M_{\mathrm{GC}}$ of $P$. fluviatilis and L. leuciscus. This may result from an increase in activity of the predator, the prey or both, at higher temperatures. Temperature optima of $c .23^{\circ} \mathrm{C}$ for P. fluviatilis (Mélard et al., 1996) and 24-30 ${ }^{\circ} \mathrm{C}$ for L. leuciscus (Staaks, 1996), which are in the upper area of the temperature range measured in this study, suggest that $P$. fluviatilis and L. leuciscus were foraging more actively at higher temperatures. But, many taxa of their benthic invertebrate prey are also more active at higher temperatures in the temperature range of this study (Wijnhoven et al., 2003), and thus may become more accessible for predators at higher temperatures.

In A. alburnus, no experimentally assessed optimum temperature could be found in the literature; however, the species is characterized as a eurytherm (Schiemer \& Waidbacher, 1992). Thus, food consumption in A. alburnus may be less affected by temperature within the temperature range experienced in this study, and also the accessibility of free-swimming planktonic food is probably less dependent on temperature than accessibility of hiding or camouflaging benthic invertebrates.

The factor site comprised all fixed differences between the three sampling locations. Even though sampling sites were chosen that were as similar as possible in their physical habitat conditions, the three sampling sites were not identical. For instance, substratum grain sizes in the shallow water were largest at LIT, and $E_{\mathrm{F}}$ and site co-varied to some extend, with LIT being the most wave-exposed habitat and GUL being the least wave-exposed habitat most of the time. These principal habitat differences were important to explain $M_{\mathrm{GC}}$ in all species. The $M_{\mathrm{GC}}$ of $P$. fluviatilis and L. leuciscus was highest at the most exposed site LIT. Furthermore, grain size of the substratum was coarsest at LIT which may have promoted feeding success of L. leuciscus on periphytic biofilms (Weatherley, 1987; Cowx, 1988). The $M_{\mathrm{GC}}$ of $A$. alburnus was highest at GUL, where $E_{\mathrm{F}}$ was generally low. Calm waters may have promoted feeding success in planktivorous A. alburnus. The results show that some proportion of the variability in the $M_{\mathrm{GC}}$ data can be explained by static differences between different habitats, which are covered by the factor site. The dynamic habitat factors $E_{\mathrm{F}}$ and temperature, however, explain a higher proportion of the variability, and thus are useful predictors of $M_{\mathrm{GC}}$.

Do the dynamic habitat variables that lead to increased gut fullness also lead to higher growth rates in the local fish populations? Differential growth rates due to dynamic habitat variables could only be found in P. fluviatilis. Perca fluviatilis grew faster in periods with high $E_{\mathrm{F}}$ as it was expected from $M_{\mathrm{GC}}$ analysis. The most pronounced increase in size occurred during sampling period six (31 August to 12 September) at LIT, where exceptionally high $E_{\mathrm{F}}$ was recorded. The resulting size difference between the local populations persisted until the end of the summer season, showing that $P$. fluviatilis are rather stationary and exchange between the local populations is low, even though LIT and GUL were on the same side of the lake and only $3 \mathrm{~km}$ apart.

No consistent correlation between $E_{\mathrm{F}}$ and growth rates could be found in L. leuciscus. High growth rates occurred for instance during sampling period one (11 to 18 July) at GUL and sampling period five (18 to 31 August) at BIR where 
maximum $E_{\mathrm{F}}$ were measured at the respective sites. This pattern was not consistent over all sampling periods and sites. Furthermore, differences in size between sampling sites did not persist over time. These findings suggest that L. leuciscus migrate greater distances than $P$. fluviatilis, such that emerging differences in body size between local populations are levelled out again within few days. In these open, changing local populations of L. leuciscus, no real growth rates could be determined, as the observed changes in size over time were caused not only by fish growth but also by emigration and immigration between local fish populations. Migrations of fish are also able to explain the decreases of average size of fish that could be observed in the local populations during some periods.

In $A$. alburnus, $M_{\mathrm{GC}}$ was independent of $E_{\mathrm{F}}$ and temperature, and accordingly, no effect of these variables on growth rates could be found. Although $M_{\mathrm{GC}}$ correlated with temperature in P. fluviatilis and L. leuciscus, no effect of temperature on growth rates was found in these species.

However, not only feeding success but also metabolic rates, however, increase with temperature (Jobling, 1994). Therefore, increased energy uptake may have been balanced by higher metabolic rates, resulting in no higher growth rates when temperatures were high. The results of this study suggest that in addition to fixed habitat attributes, dynamic variables, such as temperature and wave exposure, should be considered in studies on habitat choice of fishes in the littoral zone of lakes. This may improve the previously often limited predictive value of habitat choice models in littoral fishes.

The authors thank J. Köritzer, M. Schmid, J. Pucher, M. Döpfner, A. Weber, T. Merz and A. Meriac for help during the fishing campaign and laboratory work. This study was conducted within the Collaborative Research Centre 454 Littoral Zone of Lake Constance, partial project $\mathrm{C} 2$, which was financially supported by the German Research Foundation (DFG) and a personal grant to S.S. by the German National Academic Foundation.

\section{References}

Benson, B. J. \& Magnuson, J. J. (1992). Spatial heterogeneity of littoral fish assemblages in lakes: relation to species diversity and habitat structure. Canadian Journal of Fisheries and Aquatic Sciences 49, 1493-1500.

Białokoz, W. (1990). Evaluation of the intensity and efficiency of bleak Alburnus alburnus (L.) feeding in Tajty Lake, Masurian Lakeland, Poland. Comparative analysis of methods. Ekologia Polska 38, 163-183.

Blanchet, S., Loot, G. \& Dodson, J. J. (2008). Competition, predation and flow rate as mediators of direct and indirect effects in a stream food chain. Oecologia 157, 93-104.

Boisclair, D. \& Leggett, W. C. (1989). The importance of activity in bioenergetics models applied to actively foraging fishes. Canadian Journal of Fisheries and Aquatic Sciences 46, $1859-1867$.

Boisclair, D. \& Tang, M. (1993). Empirical analysis of the influence of swimming pattern on the net energetic cost of swimming in fishes. Journal of Fish Biology 42, 169-183.

Bryan, M. D. \& Scarnecchia, D. L. (1992). Species richness, composition, and abundance of fish larvae and juveniles inhabiting natural and developed shorelines of a glacial Iowa lake. Environmental Biology of Fishes 35, 329-341.

Chapman, R. N. (1931). Animal Ecology. New York, NY: McGraw-Hill.

Chick, J. H. \& McIvor, C. C. (1994). Patterns in the abundance and composition of fishes among beds of different macrophytes: viewing a littoral zone as a landscape. Canadian Journal of Fisheries and Aquatic Sciences 51, 2873-2882. 
Cowx, I. G. (1988). Distribution and variation in the growth of roach, Rutilus rutilus (L.), and dace, Leuciscus leuciscus (L.), in a river catchment in south-west England. Journal of Fish Biology 33, 59-72.

Debowski, P. \& Beall, E. (1995). Influence of dewatering on movements and distribution of salmon parr (Salmo salar) in relation to habitat characteristics in an experimental stream. Bulletin Français de la Pêche et Pisciculture 337/338/339, 267-275.

Dietrich, A., Baumgärtner, D. \& Eckmann, R. (2004). Competition for food between Eurasian perch (Perca fluviatilis L.) and ruffe (Gymnocephalus cernuus L.) over different substrate types. Ecology of Freshwater Fish 13, 236-244.

Fischer, P. \& Eckmann, R. (1997). Spatial distribution of littoral fish species in a large European lake, Lake Constance, Germany. Archiv für Hydrobiologie 140, 91-116.

Gabel, F., Garcia, X.-F., Brauns, M., Sukhodolov, A., Leszinski, M. \& Pusch, M. T. (2008). Resistance to ship-induced waves of benthic invertebrates in various littoral habitats. Freshwater Biology 53, 1567-1578.

Heggenes, J. (1988). Effects of short-term flow fluctuations on displacement of, and habitat use by, brown trout in a small stream. Transactions of the American Fisheries Society 117, 336-344.

Hofmann, H., Lorke, A. \& Peeters, F. (2008). The relative importance of wind and ship waves in the littoral zone of a large lake. Limnology and Oceanography 53, 368-380.

IAHR (1989). IAHR working group on wave generation and analysis: list of sea-state parameters. Journal of Waterway, Port, Coastal and Ocean Engineering 115, 793-808.

Jackson, D. A., Peres-Neto, P. R. \& Olden, J. D. (2001). What controls who is where in freshwater fish communities - the role of biotic, abiotic, and spatial factors. Canadian Journal of Fisheries and Aquatic Sciences 58, 157-170.

Jobling, M. (1994). Fish Bioenergetics. London: Chapman \& Hall.

Lewin, W.-C., Okun, N. \& Mehner, T. (2004). Determinants of the distribution of juvenile fish in the littoral area of a shallow lake. Freshwater Biology 49, 410-424.

Lienesch, P. W. \& Matthews, W. J. (2000). Daily fish and zooplankton abundances in the littoral zone of Lake Texoma, Oklahoma-Texas, in relation to abiotic variables. Environmental Biology of Fishes 59, 271-283.

Lozàn, J. L. \& Kausch, H. (1998). Angewandte Statistik für Naturwissenschaftler. Berlin: Blackwell.

Lyons, J. (1987). Distribution, abundance, and mortality of small littoral-zone fishes in Sparkling Lake, Wisconsin. Environmental Biology of Fishes 18, 93-107.

MacKenzie, B. R., Miller, T. J., Cyr, S. \& Leggett, W. C. (1994). Evidence for a domeshaped relationship between turbulence and larval fish ingestion rates. Limnology and Oceanography 39, 1790-1799.

Mélard, C., Kestemont, P. \& Grignard, J. C. (1996). Intensive culture of juvenile and adult Eurasian perch (P. fluviatilis): effect of major biotic and abiotic factors on growth. Journal of Applied Ichthyology 12, 175-180.

Pierce, C. L. (1994). Littoral fish communities in Southern Quebec lakes: relationship with limnological and prey resource variables. Canadian Journal of Fisheries and Aquatic Sciences 51, 1128-1138.

Savino, J. F. \& Stein, R. A. (1989a). Behaviour of fish predators and their prey: habitat choice between open water and dense vegetation. Environmental Biology of Fishes 24, 287-293.

Savino, J. F. \& Stein, R. A. (1989b). Behavioural interactions between fish predators and their prey: effects of plant density. Animal Behaviour 37, 311-321.

Schiemer, F. \& Waidbacher, H. (1992). Strategies for conservation of a Danubian fish fauna. In River Conservation and Management (Boon, P. J., Calow, P. \& Petts, G. E., eds), pp. 363-382. Chichester: John Wiley \& Sons.

Schiemer, F., Keckeis, H., Winkler, G. \& Flore, L. (2001). Large rivers: the relevance of ecotonal structure and hydrological properties for the fish fauna. Archiv für Hydrobiologie Supplement 135, 487-508.

Schleuter, D. \& Eckmann, R. (2008). Generalist versus specialist: the performances of perch and ruffe in a lake of low productivity. Ecology of Freshwater Fish 17, 86-99.

Schlosser, I. J. (1985). Flow regime, juvenile abundance, and the assemblage structure of stream fishes. Ecology 66, 1484-1490. 
Staaks, G. (1996). Experimental studies on temperature preference behaviour of juvenile cyprinids. Limnologica 26, 165-177.

Stoll, S., Fischer, P., Klahold, P., Scheifhacken, N., Hofmann, H. \& Rothhaupt, K.-O. (2008). Effects of water depth and hydrodynamics on the growth and distribution of juvenile cyprinids in the littoral zone of a large pre-alpine lake. Journal of Fish Biology 72, $1001-1022$.

Tonn, W. M. \& Magnuson, J. J. (1982). Patterns in the species composition and richness of fish assemblages in northern Wisconsin lakes. Ecology 63, 1149-1166.

Utne-Palm, A. C. (2004). Effects of larvae ontogeny, turbidity, and turbulence on prey attack rate and swimming activity of Atlantic herring larvae. Journal of Experimental Marine Biology and Ecology 310, 147-161.

Utne-Palm, A. C. \& Stiansen, J. E. (2002). Effect of larval ontogeny, turbulence and light on prey attack rate and swimming activity in herring larvae. Journal of Experimental Marine Biology and Ecology 268, 147-170.

Valentin, S., Sempeski, P., Souchon, Y. \& Gaudin, P. (1994). Short-term habitat use by young grayling, Thymallus thymallus L., under variable flow conditions in an experimental stream. Fisheries Management and Ecology 1, 57-65.

Vašek, M. \& Kubečka, J. (2004). In situ diel patterns of zooplankton consumption by subadult/adult roach Rutilus rutilus, bream Abramis brama, and bleak Alburnus alburnus. Folia Zoologica 53, 203-214.

Weatherley, N. S. (1987). The diet and growth of 0-group dace, Leucicus leuciscus (L.), and roach, Rutilus rutilus (L.), in a lowland river. Journal of Fish Biology 30, 237-247.

Wijnhoven, S., van Riel, M. C. \& van der Velde, G. (2003). Exotic and indigenous freshwater gammarid species: physiological tolerance to water temperature in relation to ionic content of the water. Aquatic Ecology 37, 151-158.

Wildhaber, M. L. \& Crowder, L. B. (1990). Testing a bioenergetics-based habitat choice model: bluegill (Lepomis macrochirus) response to food availability and temperature. Canadian Journal of Fisheries and Aquatic Sciences 47, 1664-1671. 